\title{
Serine-enriched minimal medium enhances conversion of selenium into selenocysteine by Streptococcus thermophilus
}

\author{
A. Castañeda-Ovando, ${ }^{1}$ J. A. Segovia-Cruz, ${ }^{1}$ J. F. Flores-Aguilar, ${ }^{1}$ G. M. Rodríguez-Serrano, ${ }^{2}$ \\ V. Salazar-Pereda, ${ }^{1}$ J. Ramírez-Godínez, ${ }^{1}$ E. Contreras-López, ${ }^{1}$ J. Jaimez-Ordaz, ${ }^{1}$ \\ and L. G. González-Olivares ${ }^{1 *}$ \\ ${ }^{1}$ Chemistry Department, Universidad Autónoma del Estado de Hidalgo, Carr. Pachuca-Tulancingo km. 4.5, Mineral de la Reforma, \\ Hgo., C.P. 42184, México \\ Biotechnology Department, Universidad Autónoma Metropolitana, Unidad Iztapalapa, AP 55-355 México D.F., México
}

\section{ABSTRACT}

Selenium is included in selenoprotein sequences, which participate in enzymatic processes necessary to preserve optimal health. Some lactic acid bacteria carry out the biotransformation of inorganic selenium in their metabolism. The complete biochemical mechanism of selenium biotransformation is still unknown; however, it is known that both the selenocysteine synthesis process and its subsequent incorporation into selenoproteins include serine as part of the action of seryl-RNAt synthetase. Therefore, the aim of this work was to determine the effect of serine during the biotransformation of selenium and the subsequence growth of Streptococcus thermophilus in a minimal medium. Two culture media were prepared, one enriched with the minimum inhibitory concentration of selenite (as $\mathrm{Na}_{2} \mathrm{SeO}_{3}$ ) and the other as a mixture of the minimum inhibitory concentration of selenite and serine. The absorbed selenium concentration was measured by inductively coupled plasma, and the selenocysteine identification was performed by reverse-phase HPLC. In the second culture medium, decreases in both times, the adaptation and the logarithmic phase, were observed. According to the results, it was possible to establish that the presence of serine allowed the biotransformation of selenite into selenocysteine by Strep. thermophilus.

Key words: selenium, biotransformation, selenocysteine, serine, Lactobacillus

\section{INTRODUCTION}

Selenium (Se) is a nonmetallic chemical element and considered an essential micronutrient for humans. Its consumption is related to the prevention and treat-

Received January 24, 2019.

Accepted March 7, 2019.

*Corresponding author: lgonzales@uaeh.edu.mx ment of some diseases (Pophaly et al., 2014; Khanam and Platel, 2016). Se deficiency in humans is rare, but evidence exists that little changes in its bioavailability have effects on human health (i.e., the immune response, neurodegeneration, cardiovascular diseases, muscular and bone disorders, Kashine Beck's disease, cancer, among others). Moreover, studies have revealed some suggestive evidence about the role that Se plays in animal and human reproduction. However, an overdose of this trace element can cause selenosis (Zhuo and Diamond, 2009; Mistry et al., 2012).

On the other hand, the inorganic form of Se is not completely bioavailable; only about 1 to $2 \%$ of the consumed selenium is absorbed by the human body. The bioavailability of Se is also affected by food thermal processing, decreasing its content due to volatilization (Navarro-Alarcón and Cabrera-Vique, 2008; Reeves and Hoffmann, 2009; Khanam and Platel, 2016). Moreover, dietary factors have a direct effect on Se bioavailability (Zhuo and Diamond, 2009); an alternative to increasing this is by seleno-AA, which are integrated into polypeptide chains of selenoproteins (Young et al., 1982).

Seleno-AA are organic compounds where selenium can be found in different organic molecules, such as selenocysteine ( $\mathbf{S e C})$, selenomethionine, and methylselenocysteine, among others.

Selenocysteine has been called the 21st AA and considered to be biologically active. The main benefits reported for the bioincorporation of Se and its subsequent conversion to $\mathrm{SeC}$ are reconstruction of bone mass, strengthening of the immune system, regulation of thyroid function, improvement of male fertility, reduced risk of contracting cancer, reduced aging, diminishment of fatigue, reduced problems of the intestinal flora, and others (Pophaly et al., 2014).

This seleno-AA differs from cysteine by the replacement of the sulfur atom with a selenium atom, presenting to $2 \mathrm{p} K_{\mathrm{a}}$ values $(5.2$ and 8.5 , respectively; Bhagavan and Ha, 2015). Furthermore, this seleno-AA 
can be produced by lactic acid bacteria (LAB; Pophaly et al., 2014) through the biotransformation of selenium, which is related to the Se inorganic species (selenate or selenide) found in the culture medium, and the growth conditions (Navarro-Alarcón and Cabrera-Vique, 2008).

The complete biochemical route to carry out the selenium biotransformation is not completely known, despite some LAB, mainly Lactobacillus, having been demonstrated to have this biotransformation capacity (Pophaly et al., 2014). In fact, 2 mechanisms have been proposed to understand this transformation. The first is based on the nonspecific incorporation of seleno-AA in polypeptide chains, which is promoted by enzymes related to sulfur metabolism, which also participate during the synthesis of selenium compounds (Rayman, 2012). The second mechanism follows the known route for some yeasts and Escherichia coli, which establishes the incorporation of selenium into proteins as a form of metabolized SeC by genetic coding (Turner et al., 1998). These proposals have provided data about the serine influence in LAB biotransformation of inorganic selenium, as well as the metabolism of some yeast (da Silva et al., 2013; Kieliszeck and Błażejak, 2013).

Streptococcus thermophilus, together with some lactobacilli, have been used as starter cultures in the production of different dairy products, such as fermented cheeses and milk. But, the added value of Se has been studied when it is incorporated in the metabolism of these microorganisms during product processes (Deng et al., 2015; Kurek et al., 2016; Shakibaie et al., 2017).

Because this mechanism as so important in improving the enrichment process of selenium in starter cultures, the aim of this study was to determine the influence of serine presence in the formation of SeC by Strep. thermophilus developed in a minimal medium enriched with inorganic selenium.

\section{MATERIALS AND METHODS}

\section{Isolation and Adaptation of Strep. thermophilus}

Streptococcus thermophilus was isolated from a commercial yogurt, in which the contents of this microorganism are declared by the producer (Danone, Paris, France). The isolation was carried out on an Agar-M17 medium (Difco Laboratories, Thermo Fisher Scientific Inc., Waltham, MA). One milliliter of yogurt was seeded in a test tube containing $9 \mathrm{~mL}$ of sterile peptone water prepared at $1 \%$. An aliquot of this dilution (100 $\mu \mathrm{L}$ ) was placed in a Petri plate, and approximately $20 \mathrm{~mL}$ of the medium was added. The medium was solidified, and then, the plates were incubated at $42^{\circ} \mathrm{C}$ for $24 \mathrm{~h}$ in anaerobic conditions (BBL GasPak Plus
Anaerobic System, Becton, Dickinson and Company, Franklin Lakes, NJ). A colony identification and microscopic morphology were carried out according to Cruz-Guerrero et al. (2014).

The streptococcal colonies were seeded in a Petri dish with Agar-M17, and after $24 \mathrm{~h}$ of incubation at $42^{\circ} \mathrm{C}$, a pure colony was placed in $10 \mathrm{~mL}$ of De Man, Rogosa, and Sharpe (MRS) broth (Difco Laboratories, Thermo Fisher Scientific Inc.) and incubated at $42^{\circ} \mathrm{C}$ for $24 \mathrm{~h}$. Subsequently, $1 \mathrm{~mL}$ of broth was placed with $1 \mathrm{~mL}$ of glycerol, and the microorganisms with glycerol were kept in storage at $-20^{\circ} \mathrm{C}$.

Isolated Strep. thermophilus were inoculated and incubated at $42^{\circ} \mathrm{C}$ for $24 \mathrm{~h}$ in MRS broth. One milliliter of preservation broth was placed in $10 \mathrm{~mL}$ of MRS broth, previously sonicated for $5 \mathrm{~min}$ to remove the oxygen excess. The culture was centrifuged at 10,000 $\times g$ at $4^{\circ} \mathrm{C}$ for $10 \mathrm{~min}$, and the pellet was washed twice with sterile phosphate buffer $(50 \mathrm{mmol} / \mathrm{L}$ at $\mathrm{pH} 6.5)$ to eliminate all remaining nutrients (Letort and Juillard, 2002; Hutkins and Goh, 2014).

\section{Incorporation of Selenium into Strep. thermophilus}

Determination of the Critical Concentration of Inhibition. A known concentration $(\mathrm{cfu} / \mathrm{mL})$ of Strep. thermophilus was inoculated from the preservation broths into $5 \mathrm{~mL}$ of MRS broth with different concentrations of selenite from Sigma-Aldrich (St. Louis, MO; as $\mathrm{Na}_{2} \mathrm{SeO}_{3}: 20,40,60,80,100,150,200,250$, and 300 $\mathrm{mg} / \mathrm{L})$. The culture medium and the selenite stock solution $(900 \mathrm{mg} / \mathrm{L})$ were prepared with sterile deionized water. The fermentation was carried out in anaerobiosis at $42^{\circ} \mathrm{C}$ for $36 \mathrm{~h}$ (BBL GasPak Plus Anaerobic System, Becton, Dickinson and Company). Later, samples were taken to measure the viable count by plating in agarMRS. The critical point of inhibition was determined according to the graphic method of Talmage and Fitch, modified by González-Olivares et al. (2016).

Preparation of Minimal Medium. The minimal medium was prepared according to Letort and Juillard (2002) with some modifications (Table 1). Cysteine (Sigma-Aldrich) was added at $0.12 \mathrm{~g} / \mathrm{L}$. Vitamins (GNC, Pittsburgh, PA) were added from a solution of complex B, achieving a final concentration of $5.275 \times$ $10^{-4} \mathrm{~g} / \mathrm{L}$; the mixture was filtered with $0.22-\mu \mathrm{m}$ sterile filters (Millipore, Billerica, MA). The lactose (SigmaAldrich) solution was sterilized independently. Cysteine and the other compounds were added to sterile deionized water, and then, the prepared solution was sterilized in an autoclave. Vitamins, lactose, and the rest of the growth-medium components were mixed under aseptic conditions. 
Strep. thermophilus Growth in Supplemented Minimal Medium. A sample of Strep. thermophilus adapted (100 cfu) was inoculated in all trials. Microorganisms were placed in test tubes containing $5 \mathrm{~mL}$ of the minimal medium enriched with the selenite inhibition critical concentration (FB). Another test was performed at the inhibition critical concentration of selenite, but here, serine (Sigma-Aldrich) was added (340 $\mathrm{mg} / \mathrm{L} ; \mathbf{F C}$ ). Additionally, a control experiment without selenite and serine was carried out (FA). All fermentations were performed at $42^{\circ} \mathrm{C}$; samples were taken of independent tubes every $2 \mathrm{~h}$ (Letort and Juillard, 2002; González-Olivares et al., 2016). Growth curves were constructed to determine the exponential phase time in each of the experiments, considering the end of the exponential phase. The selenium concentration absorbed by the microorganism and the presence and concentration of $\mathrm{SeC}$ metabolized were determined.

\section{Biomass Separation}

Biomass separation was performed according to González-Olivares and coworkers (2016). One milliliter of the fermented broth was placed in Eppendorf tubes and centrifuged at $10,000 \times g$ for $15 \mathrm{~min}$ at $4^{\circ} \mathrm{C}$. Cells were resuspended in $100 \mu \mathrm{L}$ of dithiothreitol (SigmaAldrich) prepared at $0.3 \%$ (wt/vol) to rinse the biomass and remove the selenium excess adhered to the cell membrane. Subsequently, cells were centrifuged at $10,000 \times g$ for $15 \mathrm{~min}$ at $4^{\circ} \mathrm{C}$ to remove dithiothreitol. The biomass was preserved at freezing conditions $\left(-4^{\circ} \mathrm{C}\right)$ for subsequent analysis and was labeled as conserved biomass.

Table 1. Streptococcus thermophilus minimal growth medium

\begin{tabular}{lc}
\hline Constituent & Concentration $(\mathrm{g} / \mathrm{L})$ \\
\hline Lactose & 5.00 \\
Na-acetate & 1.00 \\
$\mathrm{NH}_{4}$-citrate & 0.60 \\
$\mathrm{KH}_{2} \mathrm{PO}_{4}$ & 3.00 \\
$\mathrm{~K}_{2} \mathrm{HPO}_{4}$ & 2.50 \\
Urea & 0.24 \\
Ascorbic acid & 0.5 \\
$\mathrm{MgCl}_{2} \cdot 6 \mathrm{H}_{2} \mathrm{O}$ & 0.16 \\
$\mathrm{CaCl} \cdot 2 \mathrm{H}_{2} \mathrm{O}$ & 0.01 \\
Cysteine & 0.15 \\
Glutamine & 0.12 \\
Methionine & 0.06 \\
Leucine & 0.10 \\
Isoleucine & 0.05 \\
Valine & 0.20 \\
Pyridoxamine- $\mathrm{HCl}$ & $4 \times 10^{-4}$ \\
Nicotinic acid & $0.5 \times 10^{-4}$ \\
Riboflavin & $2.5 \times 10^{-5}$ \\
Ca-pantothenate & $0.5 \times 10^{-4}$ \\
Thiamin-HCl & $2.5 \times 10^{-6}$ \\
\hline
\end{tabular}

\section{Analysis of Absorbed Selenium}

The analysis of absorbed Se was carried out by the methodology proposed by Alzate et al. (2010) with some modifications. A total of $10 \mathrm{mg}$ of the conserved biomass was suspended in $25 \mathrm{~mL}$ of deionized water (18 $\mu \mathrm{S} / \mathrm{cm})$ and digested in an accelerated microwave reaction system (MARS 5 microwave, CEM Corporation, Matthews, NC), with a temperature gradient $\left(175^{\circ} \mathrm{C}\right.$ for $5.5 \mathrm{~min}$ and from 175 to $180^{\circ} \mathrm{C}$ for $4.5 \mathrm{~min}$ ). The pressure limit was $758.42 \mathrm{kPa}$. A Se stock solution $(50$ $\mathrm{mg} / \mathrm{L})$ in a nitric matrix $\left(5 \% \mathrm{HNO}_{3}\right)$ was used to prepare selenium standards $(0.2-3 \mathrm{mg} / \mathrm{L})$. The standards and the samples were analyzed by inductively coupled plasma (ICP)-optical emission spectrometry, using an Optima 8300 ICP-OES spectrometer from PerkinElmer (Waltham, MA), at an emission wavelength of $196 \mathrm{~nm}$.

\section{Determination of $\mathrm{SeC}$}

Carboxymethylation. Carboxymethyl-selenocysteine was used to prepare a set of $\mathrm{SeC}$ standards. A total of $50 \mathrm{mg}$ of seleno-L-cystine (Sigma-Aldrich) and 15 $\mathrm{mg}$ of $\mathrm{KBH}_{4}$ (Sigma-Aldrich) were added to $375 \mu \mathrm{L}$ of deionized water under a nitrogen atmosphere in a Schlenk flask (Anorsur, Sevilla, Spain). The reaction was carried out at $50^{\circ} \mathrm{C}$ for $1 \mathrm{~h}$. Then, $1 \mathrm{~mL}$ of iodoacetic acid (Sigma-Aldrich; $0.4 \mathrm{~mol} / \mathrm{L}$ ) was added to at $\mathrm{pH}$ 8.5 adjusted with $\mathrm{NaOH}$ (J.T. Baker, Thermo Fisher Scientific; $1 \mathrm{~mol} / \mathrm{L}$ ). The reaction was performed under a nitrogen atmosphere at $37^{\circ} \mathrm{C}$ for $1 \mathrm{~h}$ in darkness. Then, $50 \mu \mathrm{L}$ of $\beta$-mercaptoethanol (Sigma-Aldrich) was added and cooled overnight. After the carboxymethylation process, a set of $\mathrm{SeC}$ standards in the range of 0.028 to $0.62 \mathrm{mg} / \mathrm{L}$ was prepared by dilution of the reaction product.

The samples reaction sequence for carboxymethylation was the same for the standard. To break the cell wall of microorganisms, $10 \mathrm{mg}$ of conserved biomass were sonicated in an ultrasonic bath (Branson 2510, Danbury, CT) for $1 \mathrm{~h}$. After carboxymethylation, 50 $\mu \mathrm{L}$ of $6 \mathrm{~mol} / \mathrm{L} \mathrm{HCl}$ (J.T. Baker, Thermo Fisher Scientific) was added under nitrogen atmosphere to generate protein hydrolysis. The conditions of the reaction were $110^{\circ} \mathrm{C}$ for $20 \mathrm{~h}$ (Crankshaw and Grant, 1996; Turło et al., 2007).

Derivatization. The derivatization reaction was carried out by mixing $1 \mathrm{~mL}$ of borate buffer $(0.4 \mathrm{~mol} / \mathrm{L}$, $\mathrm{pH}$ 9.5), $30 \mu \mathrm{L}$ of carboxymethyl-selenocysteine solution (standard or sample), and $30 \mu \mathrm{L}$ of $o$-phthalaldehyde solution (Sigma-Aldrich; Shively, 1986; Brückner et al., 1995; Vázquez-Ortiz et al., 1995).

Chromatographic Conditions. The determination of $\mathrm{SeC}$ was performed by reverse-phase HPLC in Perki- 
nElmer Series 200 equipment. Sodium acetate buffer $(0.1 \mathrm{~mol} / \mathrm{L}, \mathrm{pH} 7.2)$ with $0.1 \%$ acetonitrile (phase A) and methanol (phase B) were used as mobile phases. All separations were performed in a Zorbax Eclipse C18 column (Agilent Technologies Inc., Santa Clara, CA; $250 \times 4.6 \mathrm{~mm}, 5 \mu \mathrm{m})$ by elution gradient $(75 \% \mathrm{~A}$ for 0-25 min, $100 \%$ B for 25-45 min; Turło et al., 2007) and detected at $340 \mathrm{~nm}$. The injection volume was 20 $\mu \mathrm{L}$, and the used flow rate was $1.0 \mathrm{~mL} / \mathrm{min}$.

\section{Statistical Analysis}

Experimental data were statistically analyzed by ANOVA, and means were compared by the Tukey's method $(P=0.05)$. The NCSS-2007 (v.07.1.15; NCSS LLC, Kaysville, UT) software was used for the statistical analysis.

\section{RESULTS AND DISCUSSION}

\section{Critical Concentration of Inhibition}

The critical concentration for Strep. thermophilus cell growth inhibition was calculated by counting colonies $(\log \mathrm{cfu} / \mathrm{mL})$ containing different selenite concentrations. Results are shown in Table 2.

The initial concentration of microorganisms was 7.51. The biomass of Strep. thermophilus decreased as higher selenite concentrations were present in the system. Total growth inhibition was observed with a selenite concentration of $200 \mathrm{mg} / \mathrm{L}$. The critical concentration of growth inhibition for the microorganism was calculated applying the Talmage and Fitch method (GonzálezOlivares et al., 2016). The selenite concentration calculated as the inhibition point was $140 \mathrm{mg} / \mathrm{L}$. Similar data were reported by Yang et al. (2018) for Strep. thermophilus, who found $80 \mathrm{mg} / \mathrm{L}$ to be the optimal selenite concentration to reach a maximum cell growth;

Table 2. Growth of Streptococcus thermophilus with different concentrations of selenite

\begin{tabular}{lc}
\hline Concentration $(\mathrm{mg} / \mathrm{L})$ & $\log \mathrm{cfu} / \mathrm{mL}$ \\
\hline 0 & $7.51 \pm 0.0$ \\
20 & $7.14 \pm 0.0$ \\
40 & $6.09 \pm 0.07$ \\
60 & $6.47 \pm 0.46$ \\
80 & $6.19 \pm 0.58$ \\
100 & $5.84 \pm 0.76$ \\
150 & $4.57 \pm 0.38$ \\
200 & 0 \\
250 & 0 \\
300 & 0 \\
\hline
\end{tabular}

besides, a decrease in cell amount was observed at 140 to $160 \mathrm{mg} / \mathrm{L}$ of sodium selenite.

Bacterial viability at high selenite concentrations was evaluated previously. Deng and coworkers (2015) carried out several experiments with Lactobacillus brevis strain CGMCC No. 6683 isolated from kefir grains, which was grown in MRS broth containing $0,0.5,1,2,5,10$, or 20 $\mathrm{mmol} / \mathrm{L}$ of selenite $(0,0.087,0.173,0.346,0.865,1.73$, or $3.46 \mathrm{~g} / \mathrm{L})$. The biomass of $L$. brevis decreased about $60 \%$ from $1 \mathrm{mmol} / \mathrm{L}(173 \mathrm{mg} / \mathrm{L})$ and more than $4 \mathrm{log}$ units at $20 \mathrm{mmol} / \mathrm{L}$ of selenite $(3.46 \mathrm{~g} / \mathrm{L})$.

According to Calomme et al. (1995), some LAB can survive in media enriched with selenite at high concentrations (up to $200 \mathrm{mg} / \mathrm{L}$ ). Besides, selenite concentrations tolerated by several LAB are variable and depend on the metabolic characteristic of each microorganism (González-Olivares et al., 2016).

The growth inhibition concentration of Strep. thermophilus has not been reported. However, the critical concentration of inhibition calculated in this study is higher than those reported for some LAB (Xia et al., 2007; González-Olivares et al., 2016; Mörschbächer et al., 2018) and lower than some growth concentrations reported for some lactobacilli (Xia et al., 2007).

\section{Strep. thermophilus Growth in Enriched Media}

Fermentations with Strep. thermophilus were performed using minimal media without Se (FA), enriched with Se (FB), and enriched with both selenite and serine (FC). All fermentations showed different adaptation and logarithmic phase times and were independent of the initial microorganism concentration.

The adaptation phase of the control group (FA) was observed until $10 \mathrm{~h}$, and the log phase was performed for $6 \mathrm{~h}$ (Figure 1A). In contrast, the minimal medium enriched with selenite and serine (Figure 1C) showed the adaptation phase faster (at $8 \mathrm{~h}$ ) than those observed in the FA and FB fermentations. In fact, FB adaptation phase (Figure 1B) was the longest in this study (16 h).

These results indicate that serine in the medium could be promoting accelerated growth of Strep. thermophilus. However, the concentration of microorganisms at the end of the logarithmic phase was lower than that obtained in experiments without serine (Figure 1B). This decrease was caused by overexpression of enzymes involved in the absorption and transformation of inorganic selenium, which has been observed in LAB and bifidobacteria discovered by Lamberti et al. (2011).

On the other hand, the adaptation of the microorganism to selenite presence influences the lengthening of the adaptation phase and affects the delay of the 
logarithmic phase (Andreoni et al., 2000). Moreover, the reduction of selenite to selenide in the fermentations was evident during the logarithmic phase; this reaction was identified in the fermentation media due to the presence of a reddish coloration during the fermentative process (Yang et al., 2017). In fact, this effect indicates a higher efficiency of the detoxification process by cells in the presence of selenite at high concentration, and it

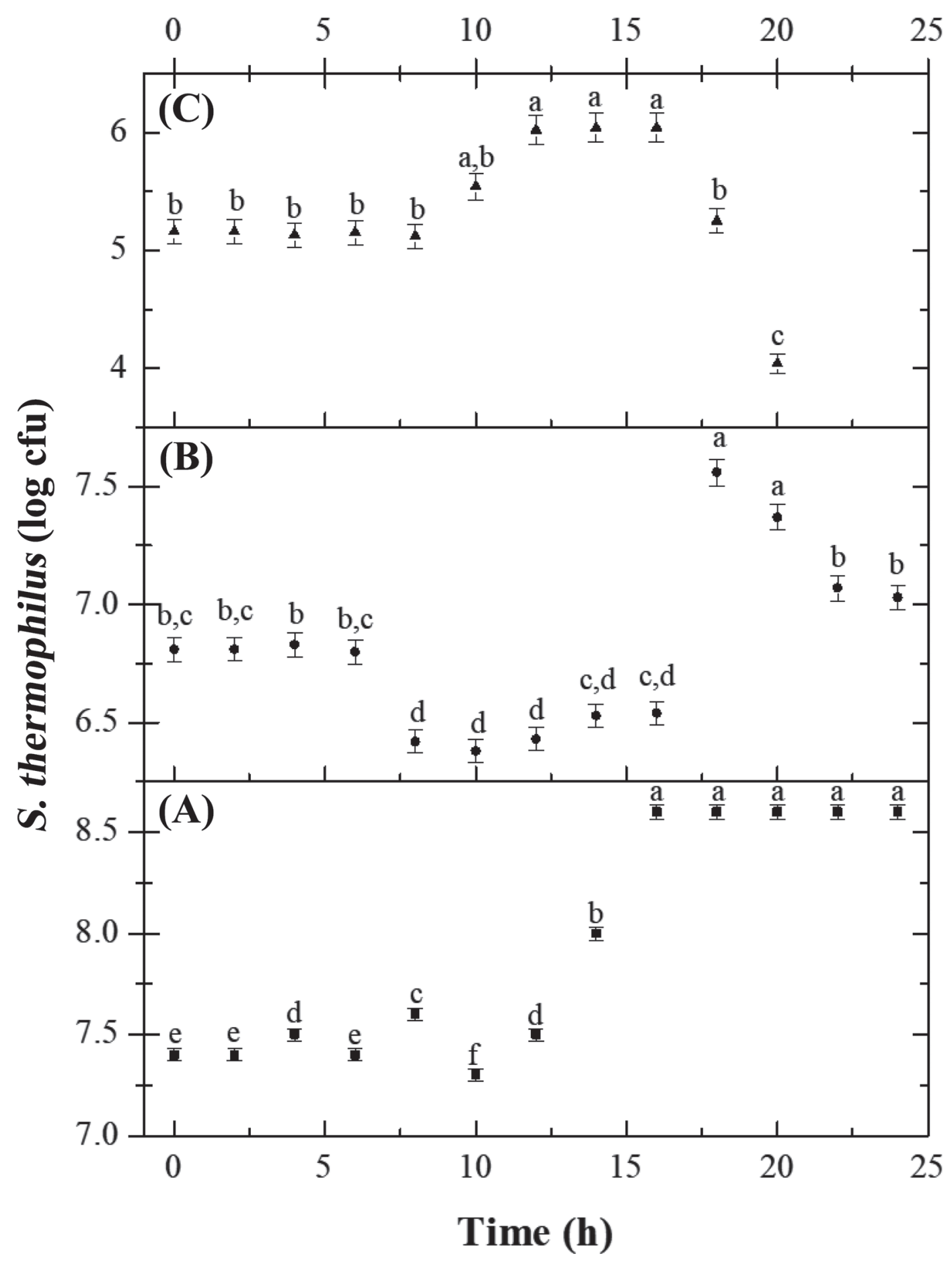

Figure 1. Growth curves of Streptococcus thermophilus developed in different media. (A) Minimal medium without supplementation (FA), (B) minimal medium supplemented by selenite (FB), and (C) minimal medium supplemented by selenite and serine (FC). Means in the same group (FA, FB, or FC) with different letters $(\mathrm{a}-\mathrm{f})$ are significantly different $(P=0.05)$. Error bars indicate SD. 
is not significant into selenium accumulation (Kieliszek et al., 2016; Yang et al., 2017).

It is likely that serine has a growth-activating effect on Strep. thermophilus. In this sense, it has been observed that some AA are essential for the development of this microorganism (Letort and Juillard, 2002). Serine is not an essential AA for its growth; however, it is known that it participates in transcription and translation processes of SeC (Hatfield and Gladyshev, 2002).

In the case of the stationary phase, Strep. thermophilus growth was lower in the presence of serine (Figures $1 \mathrm{~B}$ and $1 \mathrm{C}$ ), maybe because of the depletion of nutrients in the environment or the toxic effect exerted by the presence of selenite (Pophaly et al., 2014). This same effect was observed in the medium supplemented with just selenium salt, and it has also been reported that this microorganism can survive up to 4 wk in milk supplemented with selenite (Alzate et al., 2010).

\section{Selenium Determination by ICP}

To calculate the concentration of selenium absorbed by Strep. thermophilus, samples were re-collected considering the end of the logarithmic phase (deceleration stage), identified on each of the microbial growth curves. The remaining concentration of Se was determined after fermentation processes. The Se quantification in the unfermented culture medium and the fermented culture media, before and after removing the biomass, was performed by ICP analysis. The differences between them expressed the theoretical concentration absorbed by the cell. The obtained results are shown in Table 3.

The results demonstrated the presence of Se within the cell for the medium supplemented with selenite (FB) and those supplemented with serine and selenite (FC). According to this, similar to other LAB, Strep. thermophilus can absorb inorganic selenium from the medium, as demonstrated by Calomme et al. (1995) and Andreoni et al. (2000), and the concentration of absorbed selenium is also comparable with some absorption percentages of other LAB. Accumulation amount of Se by Strep. thermophilus has been studied previously (Yang et al., 2018), and it is close (11.56 \pm $0.25 \mathrm{mg} / \mathrm{L})$ to the value found in this research for FC fermentation (10.75 $\pm 0.51 \mathrm{mg} / \mathrm{L})$.

Although some LAB such as Lactobacillus delbrueckii ssp. bulgaricus and Lactobacillus johnsonii have lower absorption percentages than those of other LAB (González-Olivares et al., 2016), it is conclusive that most of the reports mark the capability of LAB to metabolize inorganic selenium.

It was also observed that, after $12 \mathrm{~h}$ of fermentation, the Se concentration absorbed by Strep. thermophilus in the FC medium was the highest reported for LAB $(28.58 \%)$ and is the only one reported for Strep. thermophilus. Thus, the results are coincident with those reported by Calomme et al. (1995), for L. delbrueckii, Lactobacillus plantarum, and Lactobacillus casei.

In addition, it is known that a direct relation exists between the Se concentration absorbed by LAB and the quantity of metabolized seleno-organic compounds, where the main one is SeC (Alzate et al., 2008; Palomo et al., 2014).

However, selenium accumulation by LAB within the cell is carried out through different processes, dependent on the characteristics of each species and the growth environment (Kousha et al., 2017). According to this, the selenium metabolism is carried out in 3 stages: (1) LAB take the inorganic selenium from the environment, (2) transform it into organic species, and (3) assimilate it into different biomolecules, such as proteins and carbohydrates, and as nucleic acid components (Zhang et al., 2008; Pophaly et al., 2014).

In addition, the presence of serine in the minimum medium has an influence on the absorption capacity of inorganic selenium (Table 3). Therefore, the absorption percentage was higher in fermentation with serine and selenite (FC). However, despite advances in in silico assays (Zhang et al., 2008), the mechanisms that regulate the selenium uptake in the presence of serine are still unknown, although these may be related to the mechanism used by some yeasts. In this case, the mechanism of insertion of inorganic selenium by yeasts involves the expenditure of energy for the transformation of a

Table 3. Selenium uptake by Streptococcus thermophilus with different fermentation conditions

\begin{tabular}{|c|c|c|c|c|}
\hline Fermentation $^{1}$ & $\begin{array}{l}{[\mathrm{Se}]_{\mathrm{m}}^{2}} \\
(\mathrm{mg} / \mathrm{L})\end{array}$ & $\begin{array}{c}{[\mathrm{Se}]_{\mathrm{c}}^{3} \pm \mathrm{SD}} \\
(\mathrm{mg} / \mathrm{L})\end{array}$ & $\begin{array}{c}\text { Selenium } \\
\text { absorption (\%) }\end{array}$ & $\mu \mathrm{g}$ of $\mathrm{Se} / \mathrm{cfu}$ \\
\hline$\overline{\mathrm{FA}}$ & 0 & 0 & 0 & $\mathrm{NA}^{4}$ \\
\hline $\mathrm{FB}$ & 63.92 & $6.13 \pm 0.56$ & 19.55 & 0.83 \\
\hline $\mathrm{FC}$ & 63.92 & $10.75 \pm 0.51$ & 28.58 & 1.66 \\
\hline
\end{tabular}




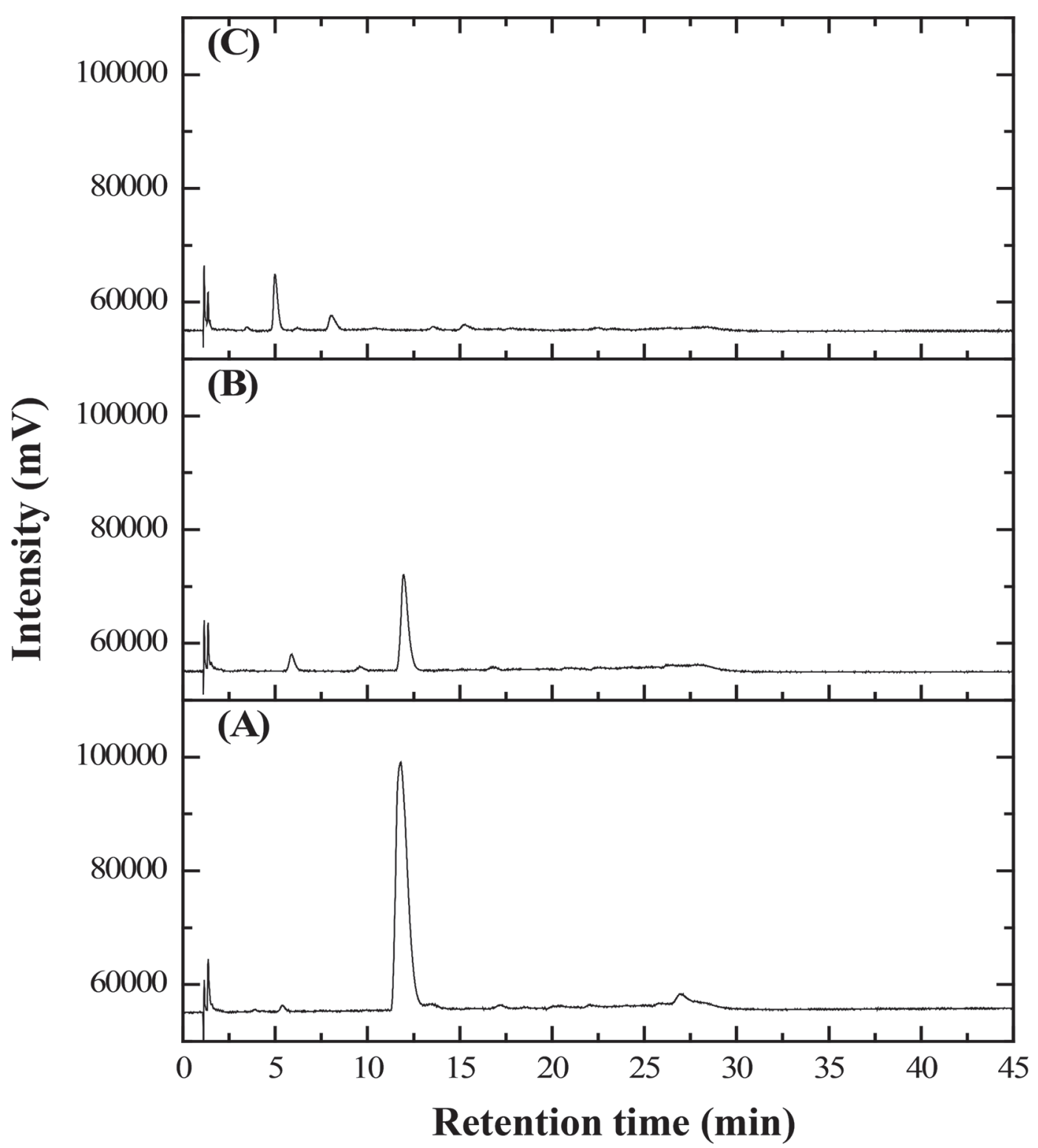

Figure 2. Chromatograms of carboxymethyl-selenocysteine detected in the standard (A) and within the cells of Streptococcus thermophilus grown in minimal medium supplemented with selenite and serine (B) and minimal medium supplemented by selenite (C).

serine-phosphate-RNA, which is the precursor for the formation of SeC (Rayman, 2004).

\section{Determination of SeC}

The concentration of SeC within the cells was determined through the identification of carboxymethyl-SeC, which was prepared from a seleno-L-cystine standard (Turło et al., 2007). Figure 2A shows the chromatogram with the retention time obtained for the seleno-cysteine derivate $(11.58 \mathrm{~min})$. This chromatogram was used to identify the $\mathrm{SeC}$ in the fermentation samples.
The quantification of $\mathrm{SeC}$ in the samples was performed by interpolation from the calibration curve (Equation 1), in which the limit of detection and the correlation coefficient were $0.028 \mathrm{mg} / \mathrm{L}$ and 0.9970 , respectively.

$$
\begin{gathered}
\text { Intensity }=4.76 \times 10^{6} \times[\text { selenocysteine }] \\
+3.64 \times 10^{4}
\end{gathered}
$$

Selenocysteine was not detectable within cell growth in the control fermentation (FA). However, the presence of $\mathrm{SeC}$ cannot be ruled out in samples where only selenite 
was added, because LAB are capable of integrating inorganic selenium as SeC (Alzate et al., 2010).

Selenocysteine within cell growth without serine (FB) was not detected (Figure 2C), even though it is known that LAB are capable of accumulating selenium and transforming it into SeC (Alzate et al., 2008, 2010).

When Strep. thermophilus was exposed to serine and selenite (FC), the amount of metabolized $\mathrm{SeC}$ was 8.36 $\pm 0.17 \mathrm{mg} / \mathrm{L}$. The chromatogram is shown in Figure 2B. The amount of selenium accumulated within cells of Strep. thermophilus was $10.75 \pm 0.51 \mathrm{mg} / \mathrm{L}$ (Table 3 ); these data were used to calculate the ratio of Se accumulation to $\mathrm{SeC}$ conversion. According to the stoichiometry between Se and SeC, 36.54\% of Se accumulated was converted to SeC. This is the first time that this kind of value has been reported.

These results show that LAB has the capability to produce $\mathrm{SeC}$ from a medium enriched with selenite; this ability to biotransform inorganic selenium to $\mathrm{SeC}$ has been reported for multiple LAB (Pophaly et al., 2014). However, the concentration of $\mathrm{SeC}$ determined by derivatization with $o$-phthalaldehyde $(8.36 \pm 0.17$ $\mathrm{mg} / \mathrm{L}$ ) shows that seleno-AA production is higher in the medium where serine was added (Figure 2B), which is the initiating AA along with selenite in the biotransformation of inorganic selenium to organic species. This behavior is just like metabolism in yeasts, where the seleno-metabolism in bacteria can start from a serine residue (Hatfield and Gladyshev, 2002; Pophaly et al., 2014). These results are in accordance with those determined by the analysis of Se accumulation by ICP because the concentration of Se absorbed by microorganisms was higher when grown in the presence of serine and selenite (FC).

In the LAB metabolism, inorganic Se is transformed into organic selenium through the substitution of sulfur in methionine and mainly in cysteine (Böck et al., 2006). The SeC analyzed in this study is associated mainly with the catalytic site of enzymes with redox activity as cofactors noncovalently attached (Stolz et al., 2006). In fact, it has been shown that inorganic selenium is integrated into intracellular proteins where the Se species measured by HPLC-ICP-MS demonstrate the presence of SeC (Alzate et al., 2008).

\section{CONCLUSIONS}

Streptococcus thermophilus can grow at selenite concentrations higher than those reported for another LAB tested previously. Serine improved selenocysteine production, and the microorganism development was faster compared with that without serine in the medium. With these results, the participation of serine in the biotransformation process of Se to selenocysteine by Strep. thermophilus was demonstrated.

\section{ACKNOWLEDGMENTS}

A. Castañeda-Ovando, G. M. Rodríguez-Serrano, J. Ramírez-Godínez, E. Contreras-López, J. Jaimez-Ordaz, and L. G. González-Olivares thank Sistema Nacional de Investigadores (CDMX, México) for the stipend received. All of the authors gratefully acknowledge Consejo Nacional de Ciencia y Tecnología (CDMX, México; project number CB-2014-241333).

\section{REFERENCES}

Alzate, A., A. Fernández-Fernández, M. C. Pérez-Conde, A. M. Gutiérrez, and C. Cámara. 2008. Comparison of biotransformation of inorganic selenium by Lactobacillus and Saccharomyces in lactic fermentation process of yogurt and kefir. J. Agric. Food Chem. 56:8728-8736. https://doi.org/10.1021/jf8013519.

Alzate, A., A. Fernández-Fernández, M. C. Pérez-Conde, A. M. Gutiérrez, and C. Cámara. 2010. Selenium-enriched fermented milk: A suitable dairy product to improve selenium intake in humans. Int. Dairy J. 20:761-769. https://doi.org/10.1016/j.idairyj .2010.05.007.

Andreoni, V., M. Moro-Luischi, L. Cavalca, D. Erbas, and S. Ciapellano. 2000. Selenite tolerance and accumulation in Lactobacillus species. Ann. Microbiol. 50:77-88.

Bhagavan, N. V., and C.-E. Ha. 2015. Chapter 3-Amino acids. Pages 21-29 in Essentials of Medical Biochemistry: With Clinical Cases. 2nd. ed. Elsevier, Burlington, MA. https://doi.org/10.1016/B978 -0-12-416687-5.00003-8.

Böck, A., M. Rother, M. Leibundgut, and N. Ban. 2006. Selenium metabolism in prokaryotes. Pages $9-28$ in Selenium. D. L. Hatfield, M. J. Berry, and V. N. Gladyshev, ed. Springer, Boston, MA. https://doi.org/10.1007/0-387-33827-6_2.

Brückner, H., M. Langer, M. Lüpke, T. Westhauser, and H. Godel. 1995. Liquid chromatographic determination of amino acid enantiomers by derivatization with $o$-phthaldialdehyde and chiral thiols applications with reference to food science. J. Chromatogr. A 697:229-245. https://doi.org/10.1016/0021-9673(94)01052-G.

Calomme, M. R., K. Van den Branden, and D. A. Vanden Berghe. 1995. Selenium and Lactobacillus species. J. Appl. Microbiol. 79:331-340. https://doi.org/10.1111/j.1365-2672.1995.tb03145.x.

Crankshaw, M. W., and G. A. Grant. 1996. Modification of cysteine Curr. Prot. Protein Sci. 3:15.1.1-15.1.18. https://doi.org/10.1002/ 0471140864.ps1501s03.

Cruz-Guerrero, A., H. Hernández-Sánchez, G. Rodríguez-Serrano, L. Gómez-Ruiz, M. García-Garibay, and I. Figueroa-González. 2014 Commercial probiotic bacteria and prebiotic carbohydrates: A fundamental study on prebiotics uptake, antimicrobials production and inhibition of pathogens. J. Sci. Food Agric. 94:2246-2252. https://doi.org/10.1002/jsfa.6549.

da Silva, M. T. A., V. E. A. Caldas, F. C. Costa, O. H. Silvestre, and D. A. M. M. Thiemanna. 2013. Selenocysteine biosynthesis and insertion machinery in Naegleria gruberi. Mol. Biochem. Parasitol. 188:87-90. https://doi.org/10.1016/j.molbiopara.2013.04.002.

Deng, Y., C. Man, Y. Fan, Z. Wang, L. Li, H. Ren, W. Cheng, and Y. Jiang. 2015. Preparation of elemental selenium-enriched fermented milk by newly isolated Lactobacillus brevis from kefir grains. Int. Dairy J. 44:31-36. https://doi.org/10.1016/j.idairyj.2014.12.008.

González-Olivares, L. G., E. Contreras-López, J. F. Flores-Aguilar, G. M. Rodríguez-Serrano, A. Castañeda-Ovando, J. Jaimez-Ordaz, J. Añorve-Morga, and A. E. Cruz-Guerrero. 2016. Inorganic selenium uptake by Lactobacillus ssp. Rev. Mex. Ing. Quim. 15:33-38. 
Hatfield, D. L., and V. N. Gladyshev. 2002. How selenium has altered our understanding of the genetic code. Mol. Cell. Biol. 22:35653576. https://doi.org/10.1128/MCB.22.11.3565-3576.2002.

Hutkins, R., and Y. J. Goh. 2014. Streptococcus: Streptococcus thermophilus. Pages 554-559 In Encyclopedia of Food Microbiology. 2nd ed. Elsevier Inc., Amsterdam, the Netherlands. https://doi .org/10.1016/B978-0-12-384730-0.00325-6.

Khanam, A., and H. Platel. 2016. Bioaccessibility of selenium, selenomethionine and selenocysteine from foods and influence of heat processing on the same. Food Chem. 194:1293-1299. https://doi .org/10.1016/j.foodchem.2015.09.005.

Kieliszek, M., and S. Błażejak. 2013. Selenium: Significance, and outlook for supplementation. Nutrition 29:713-718. https://doi.org/ 10.1016/j.nut.2012.11.012.

Kieliszek, M., S. Blazejak, and M. Placzek. 2016. Spectrophotometric evaluation of selenium binding by Saccharomyces cerevisiae ATCC MYA-2200 and Candida utilis ATCC 9950 yeast. J. Trace Elem. Med. Biol. 35:90-96. https://doi.org/10.1016/j.jtemb.2016.01.014.

Kousha, M., S. Yeganeh, and A. K. Amirkolaie. 2017. Effect of sodium selenite on the bacteria growth, selenium accumulation, and selenium biotransformation in Pediococcus acidilactici. Food Sci. Biotechnol. 26:1013-1018. https://doi.org/10.1007/s10068-017 $-0142-y$.

Kurek, E., A. Ruszczynska, M. Wojciechowski, A. Luciuk, M. Michalska-Kacymirow, I. Motyl, and E. Bulska. 2016. Bio-transformation of selenium in Se-enriched bacterial strains of Lactobacillus casei. Rocz. Panstw. Zakl. Hig. 67:253-262.

Lamberti, C., E. Mangiapane, A. Pessione, R. Mazzoli, C. Giunta, and E. Pessione. 2011. Proteomic characterization of a selenium-metabolizing probiotic Lactobacillus reuteri $\mathrm{Lb} 2 \mathrm{BM}$ for nutraceutical applications. Proteomics 11:2212-2221. https://doi.org/10.1002/ pmic.201000747.

Letort, C., and V. Juillard. 2002. Development of a minimal chemically-defined medium for the exponential growth of Streptococcus thermophilus. J. Appl. Microbiol. 91:1023-1029. https://doi.org/10 .1046/j.1365-2672.2001.01469.x.

Mistry, H. D., F. Broughton, C. W. G. Redman, and L. Poston. 2012. Selenium in reproductive health. Am. J. Obstet. Gynecol. 206:2130. https://doi.org/10.1016/j.ajog.2011.07.034.

Mörschbächer, A. P., A. Dullius, C. H. Dullius, C. R. Bandt, D. Kuhn, D. T. Brietzke, F. J. Malmann Kuffel, H. Pretto Etgeton, T. Altmayer, T. Engelmann Gonçalves, Y. A. Schweizer, E. Quadro Oreste, A. Schwingel Ribeiro, D. Neutzling Lehn, C. F. Volken de Souza, and L. Hoehne. 2018. Assessment of selenium bioaccumulation in lactic acid bacteria. J. Dairy Sci. 101: 10626-10635. https: //doi.org/10.3168/jds.2018-14852.

Navarro-Alarcón, M., and C. Cabrera-Vique. 2008. Selenium in food and the human body: A review. Sci. Total Environ. 400:115-141. https://doi.org/10.1016/j.scitotenv.2008.06.024.

Palomo, M., A. M. Gutiérrez, M. C. Pérez-Conde, C. Cámara, and Y. Madrid. 2014. Se metallomics during lactic fermentation of Se-enriched yogurt. Food Chem. 164:371-379. https://doi.org/10.1016/ j.foodchem.2014.05.007.

Pophaly, S. D., P. Singh, H. Kumar, S. Kumar, and R. Singh. 2014. Selenium enrichment of lactic acid bacteria and bifidobacteria: A functional food perspective. Trends Food Sci. Technol. 39:135-145. https://doi.org/10.1016/j.tifs.2014.07.006.
Rayman, M. P. 2004. The use of high-selenium yeast to raise selenium status: How does it measure up? Br. J. Nutr. 92:557-573. https:// doi.org/10.1079/BJN20041251.

Rayman, M. P. 2012. Selenium and human health. Lancet 379:12561268. https://doi.org/10.1016/S0140-6736(11)61452-9.

Reeves, M. A., and P. R. Hoffmann. 2009. The human selenoproteome: Recent insights into functions and regulation. Cell. Mol. Life Sci. 66:2457-2478. https://doi.org/10.1007/s00018-009-0032-4.

Shakibaie, M., T. Mohammadi-Khorsand, M. Adeli-Sardou, M. Jafari, S. Amirpour-Rostami, A. Ameri, and H. Forootanfar. 2017. Probiotic and antioxidant properties of selenium-enriched Lactobacillus brevis LSe isolated from an Iranian traditional dairy product. J. Trace Elem. Med. Biol. 40:1-9. https://doi.org/10.1016/j.jtemb 2016.11.013.

Shively, J. E. 1986. Methods of Protein Microcharacterization. A Practical Handbook. Humana Press Inc., Clifton, NJ. https://doi.org/ 10.1007/978-1-59259-436-8.

Stolz, J. F., P. Basu, J. M. Santini, and R. S. Oremland. 2006. Arsenic and selenium in microbial metabolism. Annu. Rev. Microbiol 60:107-130. https://doi.org/10.1146/annurev.micro.60.080805 .142053 .

Turło, J., B. Gutkowska, and E. Malinowska. 2007. Relationship between the selenium, selenomethionine, and selenocysteine content of submerged cultivated mycelium of Lentinula edodes (Berk). Acta Chromatogr. 18:36-48.

Turner, R. J., J. H. Weiner, and D. E. Taylor. 1998. Selenium metabolism in Escherichia coli. Biometals 11:223-227. https://doi.org/10 .1023/A:1009290213301.

Vázquez-Ortiz, F., G. Caire, I. Higuera-Ciaparra, and G. Hernández. 1995. High performance liquid chromatographic determination of free amino acids in shrimp. J. Liq. Chromatogr. Relat. Technol. 18:2059-2068. https://doi.org/10.1080/10826079508013960.

Xia, S. K., L. Chen, and J. Q. Liang. 2007. Enriched selenium and its effects on growth and biochemical composition in Lactobacillus bulgaricus. J. Agric. Food Chem. 55:2413-2417. https://doi.org/ 10.1021/jf062946j.

Yang, J., Y. Li, L. Zhang, M. Fan, and X. Wei. 2017. Response surface design for accumulation of selenium by different lactic acid bacteria. 3 Biotech 7:52. https://doi.org/10.1007/s13205-017-0709-6.

Yang, J., J. Wang, K. Yang, M. Liu, Y. Qi, T. Zhang, M. Fan, and X. Wei. 2018. Antibacterial activity of selenium-enriched lactic acid bacteria against common food-borne pathogens in vitro. J. Dairy Sci. 101:1930-1942. https://doi.org/10.3168/jds.2017-13430.

Young, V. R., A. Nahapetian, and M. Janghorbani. 1982. Selenium bioavailability with reference to human nutrition. Am. J. Clin. Nutr. 35:1076-1088. https://doi.org/10.1093/ajcn/35.5.1076.

Zhang, Y., A. A. Turanov, D. L. Hatfield, and V. N. Gladyshev. 2008. In silico identification of genes involved in selenium metabolism: Evidence for a third selenium utilization trait. BMC Genomics 9:251. https://doi.org/10.1186/1471-2164-9-251.

Zhuo, P., and A. M. Diamond. 2009. Molecular mechanisms by which selenoproteins affect cancer risk and progression. Biochim. Biophys. Acta 1790:1546-1554. https://doi.org/10.1016/j.bbagen .2009.03.004. 